\title{
Evaluation of Rice Husk Use Scenarios Incorporating Stakeholders' Preferences Revealed through the Analytic Hierarchy Process in An Giang Province, Vietnam
}

\author{
Pham Thi Mai Thao ${ }^{*}$, Kiyo H. Kurisu², Keisuke Hanaki ${ }^{1}$ \\ ${ }^{1}$ Department of Urban Engineering, School of Engineering, The University of Tokyo, Tokyo, Japan \\ ${ }^{2}$ Research Center for Advanced Science and Technology, The University of Tokyo, Tokyo, Japan \\ Email: *ptmthao@gmail.com
}

Received 9 June 2014; revised 5 July 2014; accepted 1 August 2014

Copyright (C) 2014 by authors and Scientific Research Publishing Inc.

This work is licensed under the Creative Commons Attribution International License (CC BY).

http://creativecommons.org/licenses/by/4.0/

\section{(c) (i) Open Access}

\section{Abstract}

To process biomass energy successfully, it is necessary to incorporate a number of criteria that can be assessed either quantitatively or qualitatively for various biomass scenarios. It is also important to take into account the local people's preferences and interests in the decision-making process. In this study, preferences of various stakeholders on rice husk use, such as urban households, rural households, rice mill owners, brick kiln owners, government officials, and scientists, were investigated using the Analytic Hierarchy Process. The results were incorporated with objective evaluation that was derived from Life Cycle Assessment. A holistic evaluation of rice-husk use scenarios was conducted. The results showed that rural households, rice mill owners, and brick kiln owners still want to use rice husk in conventional ways, while urban households, government officials, and scientists prefer to use rice husk with new technologies. The results reveal the aspects that each stakeholder thinks important and the conflicts between stakeholders. These can help government officials grasp the preferences of the local people which is important information for decision-making.

\section{Keywords}

Rice Husk, Stakeholder, AHP, Decision-Making

\section{Introduction}

Rice husk is one of the most widely available agricultural biomass in many rice-producing countries. Promoting

${ }^{*}$ Corresponding author.

How to cite this paper: Thao, P.T.M., Kurisu, K.H. and Hanaki, K. (2014) Evaluation of Rice Husk Use Scenarios Incorporating Stakeholders' Preferences Revealed through the Analytic Hierarchy Process in An Giang Province, Vietnam. Low Carbon Economy, 5, 95-104. http://dx.doi.org/10.4236/Ice.2014.53010 
the use of rice husks instead of fossil fuels would contribute to $\mathrm{CO}_{2}$ reduction and economic benefits. Actually, several pre-feasibility studies were carried out to install rice husk power plants in Viet Nam [1]-[4]. In addition to direct burning for energy production, other innovative rice-husk-use technologies such as gasification and pyrolysis have also been developed. However, when innovative technologies are actually installed in a target area, local people sometimes have difficulties in accepting them. To launch a biomass project successfully, the project needs to take into account the local people's preferences and interests in the decision making process [5].

An Giang province is situated in the Mekong River Delta region, which has the largest paddy area in Vietnam (with 520,000 ha in use [6]) and therefore can be a potential market place for rice husk energy production. In our previous studies, we have developed 18 scenarios for rice-husk use; we have also estimated greenhouse gases (GHGs) mitigation and cost reduction potentials using Life Cycle Assessment (LCA) [7] [8]. The results indicated that the win-win scenarios that achieve both large $\mathrm{CO}_{2}$ mitigation and cost reduction are traditional cooking use, large-scale combustion, and small-scale gasification. However, it is also important to make clear the stakeholders' preferences not only on environmental and economic aspects but also on other qualitative aspects such as safety and convenience of the target technologies. A holistic evaluation that includes the local people's preferences can give a more realistic picture of rice husk use in the target region.

Analytic Hierarchy Process (AHP) is a decision-making tool developed in the 1970s by Thomas L. Saaty of the University of Pittsburgh. AHP is one of the most widely accepted methods used in multi-criteria analysis to evaluate people's preferences [9]. The main advantage of AHP is the ease with which stakeholders can evaluate various attributes through simple pair-wise comparisons. The AHP is a rapid and low-cost approach that allows much smaller sample size than other methods such as contingent valuation method and conjoint analysis [10]. On the other hand, the disadvantage of AHP is the lack of statistical method to evaluate the results, although the consistency of the participants' responses can be analyzed using a consistency index (CI). In this study, the sample size is small because the questionnaire survey must be conducted through a face-to-face interview, especially in the rural areas. As such, AHP is selected as the appropriate method to evaluate the stakeholders' preferences. We applied the AHP procedure to make clear the different preferences of the various stakeholder groups. This allowed us to develop a holistic evaluation framework for the rice-husk use scenarios in An Giang Province.

\section{Methods}

\subsection{Target Technologies and Scenarios}

Table 1 and Figure 1 show the various rice-husk use scenarios developed in our previous studies. Rice husk can be used for direct combustion, gasification, and pyrolysis as well as for traditional uses like cooking and brick production. To overcome the disadvantages of bulkiness, rice husk can be also be compressed as briquettes. The detailed fuel allocations based on supply and demand in An Giang Province are shown in our previous study [8].

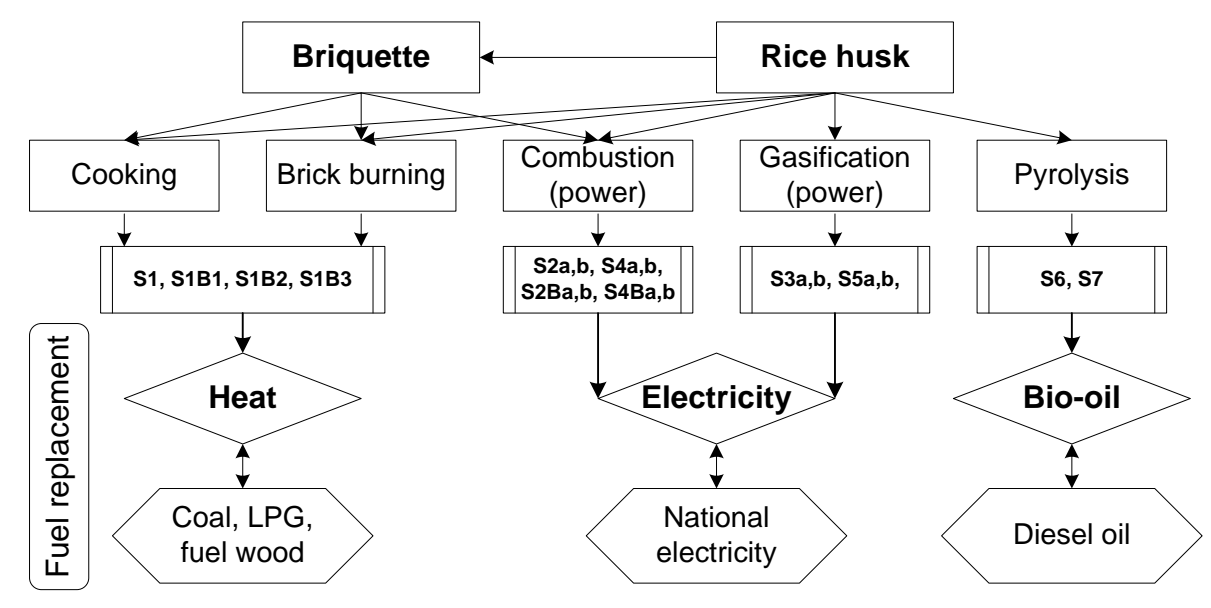

Figure 1. Scenarios of the different uses of rice husk and briquette. 
Table 1. Scenario description.

\begin{tabular}{ccccc}
\hline Scenario & Technology & Capacity & Feeding stocks & Target rice husk amount \\
S1 & & Rice husk & Excess $^{*}$ \\
S1B1 & Cooking & & Rice husk briquette & All \\
S1B2 & & Rice husk briquette & Excess \\
S1B3 & & Rice husk briquette & Excess + cooking \\
S2a & $5 \mathrm{MW}$ & Rice husk & Excess \\
S4a & $5 \mathrm{MW}$ & Rice husk & All \\
S2Ba & & $5 \mathrm{MW}$ & Rice husk briquette & Excess \\
S4Ba & Combustion & $5 \mathrm{MW}$ & Rice husk briquette & All \\
S2b & power plant & $30 \mathrm{MW}$ & Rice husk & Excess \\
S4b & & $30 \mathrm{MW}$ & Rice husk & All \\
S2Bb & & $30 \mathrm{MW}$ & Rice husk briquette & Excess \\
S4Bb & & $30 \mathrm{MW}$ & Rice husk briquette & All \\
S3a & & $5 \mathrm{MW}$ & Rice husk & Excess \\
S5a & Gasification & $5 \mathrm{MW}$ & Rice husk & All \\
S3b & power plant & $30 \mathrm{MW}$ & Rice husk & All \\
S5b & & $30 \mathrm{MW}$ & Rice husk & All \\
S6 & & & Rice husk & Rice husk \\
S7 & Pyrolysis & & & \\
\hline S & & & & \\
\hline
\end{tabular}

*[Excess rice husk $]=$ [All generated rice husk $]-$ [Current demand for cooking and brick making].

\subsection{Hierarchy Structure and Scenario Evaluation Framework}

The first step in AHP is to build a hierarchy structure for the target objective. The objective should be placed at the top of the hierarchy, while the important attributes to determine the objective are placed in the second layer. The second layer attributes can be divided into sub-attributes, which are placed in the third layer. This way, the breakdown of each attribute can be made. Finally, alternative scenarios are placed at the bottom of the hierarchy. All attributes and scenarios are connected by lines; a pair-wise question is needed for each line to estimate the weight of importance.

The basic hierarchy considered in this study is shown in Figure 2. The objective for this study, which is placed on top, should be "evaluation of rice-husk use". The important aspects for the objective are "environmental impacts", "cost”, "safety", and "convenience", which are placed in the second layer. "Environmental impact" can be divided into "global warming", "water pollution", "air pollution", and "waste generation"; these aspects are then placed in the third layer. Then, the developed 18 scenarios can be placed at the bottom.

However, if the basic procedure is applied into weighting the 18 scenarios, the number of pair-wises becomes too huge: six $\left({ }_{4} \mathrm{C}_{2}\right)$ for four attributes, six $\left({ }_{4} \mathrm{C}_{2}\right)$ for four sub-attributes, and $1071\left(7 *{ }_{18} \mathrm{C}_{2}\right)$ for 18 alternative scenarios are needed, resulting in 1083 pair-wise questions. This number is not realistic for the face-to-face questionnaire survey. Besides the huge number of pair-wises, it is difficult for people to compare the scenario itself because each scenario has various fuel allocations. To reduce the pair-wise number and evaluate all scenarios, the AHP procedure was modified.

As shown in Figure 3, the hierarchy was modified to include only each attribute without the scenario evaluation. The modified AHP needs six pair-wises for four attributes and 22 pair-wises for sub-attributes, resulting in only 28 pair-wises in total.

When the scenarios are separated from the hierarchy structure, the evaluation method for each scenario must be prepared. Figure 4 shows the framework of the scenario evaluation. The scenarios are ranked using LCA re- 


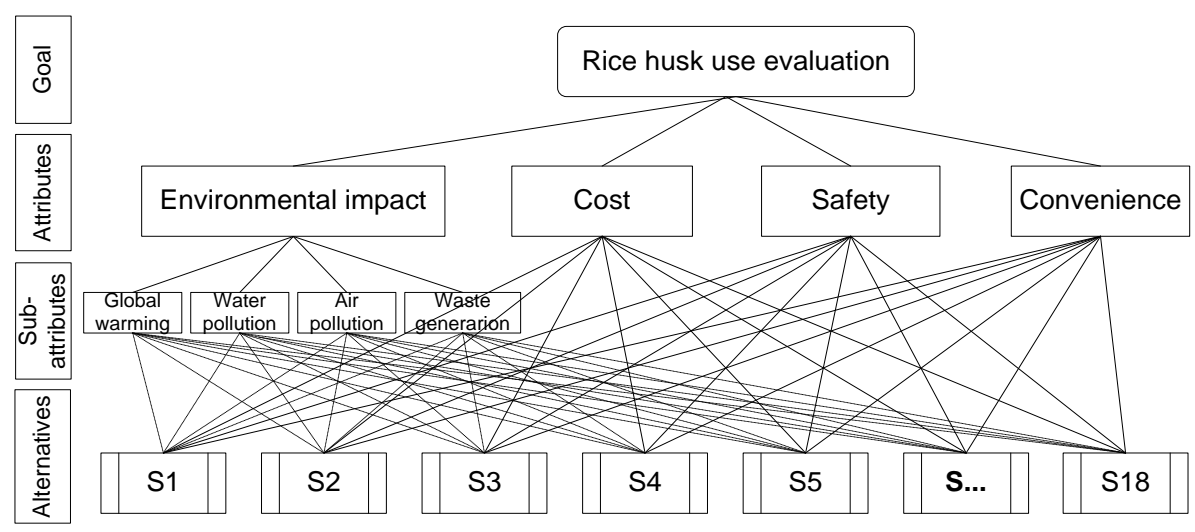

Figure 2. Basic hierarchy structure of AHP.

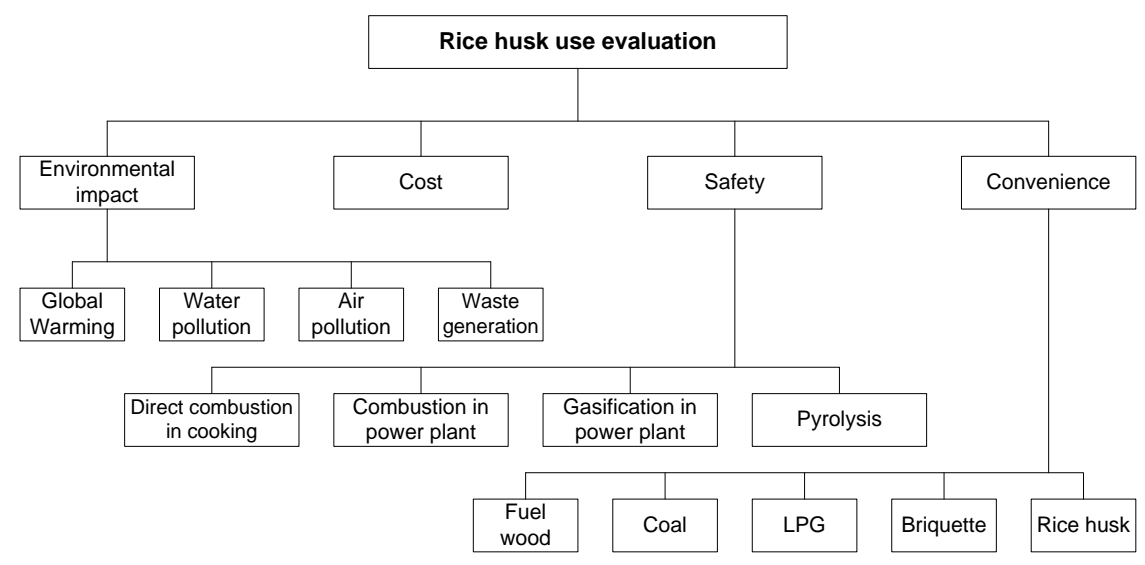

Figure 3. Modified hierarchy structure of AHP.

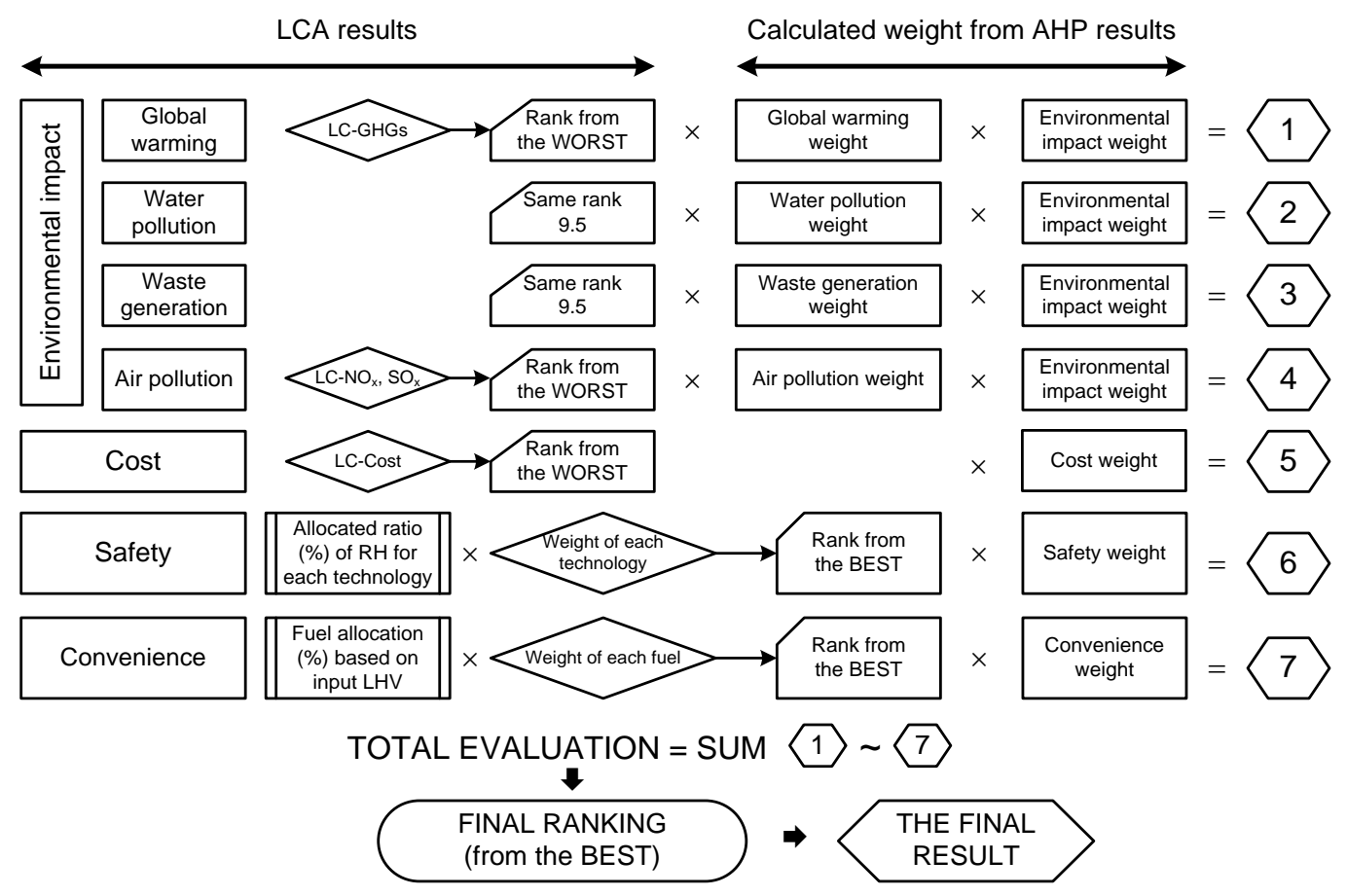

Figure 4. Holistic scenario evaluation framework. 
sults or fuel allocation, and then AHP-weights are multiplied. From the viewpoints of "global warming”, "air pollution", and "cost", the scenarios are ranked based on LCA estimation [7] [8]. For "water pollution" and "waste generation", the importance of each scenario is assumed to be the same and equal ranks are adopted for all the scenarios. For "safety", the allocated ratio (\%) of rice husk for each technology was multiplied by the AHP-weight of each technology. For "convenience", the fuel allocation (\%) based on the inputted low heating values was multiplied by the AHP-weight of each fuel, and the scenarios are ranked from the best. The rank of each attribute is multiplied by the AHP-weight of the attribute, and the seven indexes are calculated. For example, in the case of "global warming", the scenarios were ranked from the worst based on the LC-GHG results [7] and the rank was multiplied with the "global warming" weight and the "environmental impact" weight derived from AHP, resulting in the index of global warming. After calculating the seven indexes, they are summed-up and the final evaluation index is gained.

To evaluate each scenario based on the above procedure, sub-attributes for "safety" and "convenience" are set up as shown in Figure 3. Since each scenario has fuel allocation for each technology and fuel, the technologies and fuels are placed as sub-attributes under "safety" and "convenience", respectively.

\subsection{Questionnaire Design and Answer Method of a Pair-Wise Question}

The questionnaire consists of three parts. In the first part, the demographics, such as sex, age, education, and income, are asked. In the following section, explanations about questionnaire objectives, environmental impact, cost, safety, and convenience features, and the various ways rice husk may be used, are provided. From this section, an interviewee can fully understand the aims of the questionnaire. Interviewees were also given explanations about terminologies that were used in the questionnaire. In the last part, 28 pair-wise questions are asked to clarify the respondent's preference. The base questions asked are as follows:

[Question 1] "From the viewpoint of effective rice husk use, which indicator do you think is more important?”

[Question 2] "From the viewpoint of environmental impact, which impact do you think is more important?"

[Question 3] "From the viewpoint of safety, which technology do you like more?"

[Question 4] "From the viewpoint of convenience, which fuel do you like more?"

An example of pair-wise question between "global warming" and "air pollution" from the point of view of "environmental impact" is shown in Figure 5.

\subsection{Stakeholder Selection}

Regarding the use of rice husk, six different stakeholders were selected: rural households (Rural-H), urban households (Urban-H), rice mill owners (RMO), brick kiln owners (BKO), government officials (GOV), and scientists (SCI). For the selection of respondents, random sampling was used except for GOV and SCI. Rural-H and Urban-H respondents were selected from the address lists of 4 rural districts (Cho Moi, Thoai Son, Chau Thanh, and Chau Phu) and 2 towns (Long Xuyen City and Chau Doc Town), respectively. The respondents were selected in a fixed interval from the address lists by the local government. RMO and BKO were chosen from the rice mills and brick kilns registered in the People Committee Office. The total numbers of rice husk mills with capacities above $100 \mathrm{t} / \mathrm{d}$ and brick kilns in the target area are about 200 and 300, respectively. Among them, we randomly selected 20 mills and 20 kilns. The chairs, vice-chairs, and managers at the provincial and district levels, as well as managers from the Department of Nature and Environment and the Department of Science and Technology were selected for GOV. For SCI, professors from the School of Technology and from the School of Economics in An Giang University who well know about the local situation about rice husk were selected. The sample size for each stakeholder is shown in Table 2.

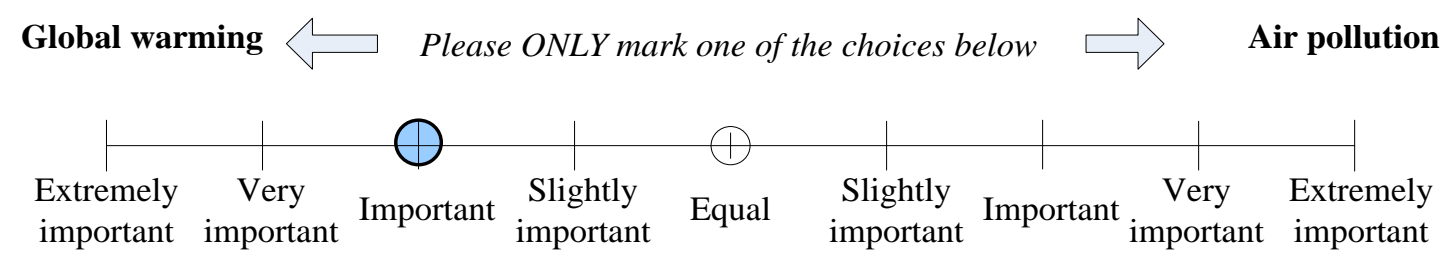

Figure 5. Example of a pair-wise question. 
Table 2. Selection of stakeholders.

\begin{tabular}{cccc}
\hline No & Stakeholder & Symbol & Sample size \\
\hline 1 & Urban household & Urban-H & $30^{[i]}$ \\
2 & Rural household & Rural-H & $40^{[i i]}$ \\
3 & Rice mill owner & RMO & 20 \\
4 & Brick kiln owner & BKO & 20 \\
5 & Governor & GOV & 10 \\
6 & Scientist & SCI & 10 \\
\hline
\end{tabular}

Note: ${ }^{[\mathrm{i}]} 15$ males and 15 females from 20 to 50 years old; ${ }^{\left[{ }^{[i]}\right]} 20$ males and 20 females from 20 to 50 years old.

\subsection{Survey Method}

The questionnaire surveys were conducted from November 23 to December 18, 2013 in the An Giang Province through face-to-face interviews. Five An Giang university students were trained as interviewers to help in the survey. An interview lasted $1.5 \mathrm{hr}$ or more.

\subsection{Procedure of Calculation}

The weight of each attribute was calculated following the eigen-vector procedure [9]. After obtaining the pairwise judgments, Saaty's scale ( 9 to $1 / 9$ ) is applied to change the results into a pair-wise matrix. The normalized matrix is gained by dividing each element by the column-wise summation of the elements. Then, the eigen-vector is calculated by averaging the element in rows. Each element of this vector represents the weight of importance. The eigen-value $\left(\lambda_{\max }\right)$ is determined by using the relationship, $\mathrm{Aw}=\lambda_{\max } \mathrm{w}$. Then, the consistency index $(C I)$ was calculated based on the following equation:

$$
C I=\frac{\lambda_{\max }-n}{n-1}
$$

$n$ : number of evaluating factor.

$\lambda_{\max }$ : the maximum eigen-value of the matrix.

$C I$ is used to determine and justify the inconsistency in the pair-wise comparisons made by the respondents. If $C I=0$, then the answers of the respondent is completely consistent; if $C I=1$, then the answers are completely inconsistent. Saaty suggested that answers within $C I \leq 0.1$ are acceptable. However, in practice, a $C I$ of more than 0.1 has sometimes been accepted [11]. Some previous studies used 0.2 instead of 0.1 as $C I$ criterion [12] [13]. In this study, a $C I$ criterion of 0.2 was used. Answers with $C I \geq 0.2$ were excluded as inconsistent.

\section{Results}

\subsection{Preference on Each Attribute Based on AHP}

Figures 6-9 show the estimated weight for each attribute. The figure shown in each column represents the weight of importance of the attributes, which was calculated based on the eigen-vector procedure. When the attributes from the viewpoint of "effective rice husk use" in the second level were compared (Figure 6), "safety" was given the highest priority by Rural-H, Urban-H, and GOV, while "cost" was given less priority. On the other hand, the business people, such as RMO and BKO gave the highest priority on "cost". They put off the environmental features of rice husk use. The stakeholders' prioritization of the different environmental issues is shown in Figure 7. "Water pollution" was given the most attention by almost all stakeholders and only SCI made "air pollution" the first priority. Figure 8 shows the stakeholders' preferences on the different technologies from the viewpoint of "safety". The preferences varied among the different stakeholders. Rural-H gave highest preference on conventional technologies, such as cooking and brick making. On the other hand, GOV gave the lowest priority on conventional technologies and gave high priority on innovative technologies relating to power generation. Similar preferences for the new technologies were also found in Urban-H. From the viewpoint of "convenience", as shown in Figure 9, the priority weights of LPG were quite high, ranging from 0.37 to 0.51 among 


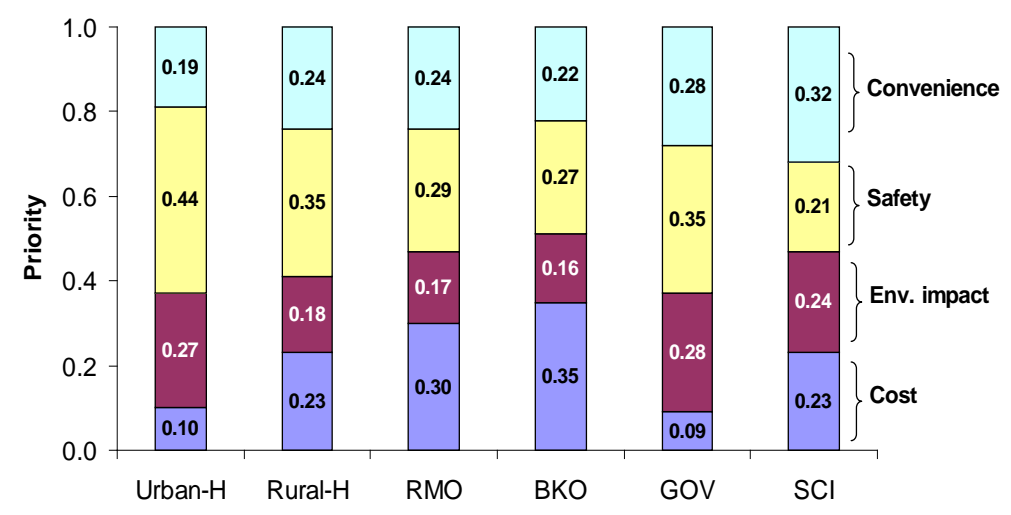

Figure 6. Comparison of "effective aspects”.

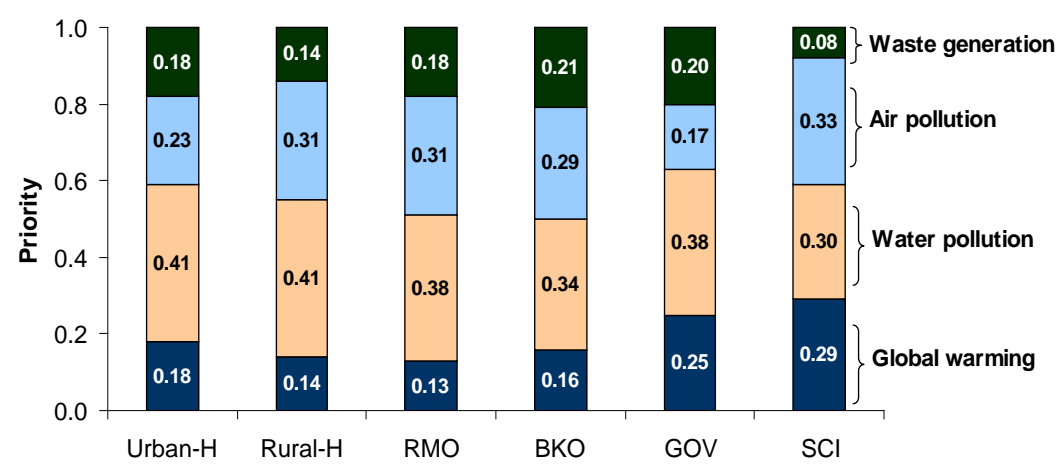

Figure 7. Comparison of "environmental aspects".

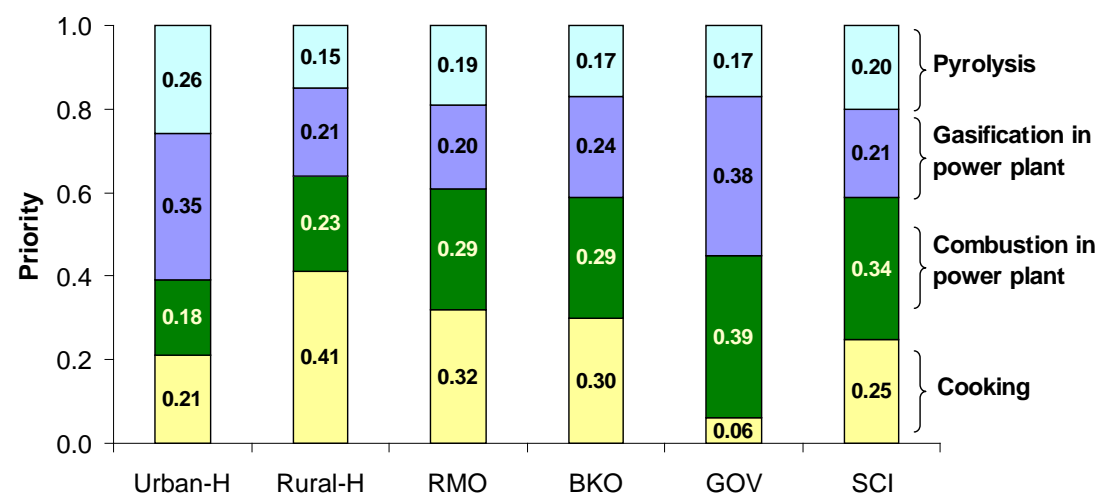

Figure 8. Comparison of "safety aspects".

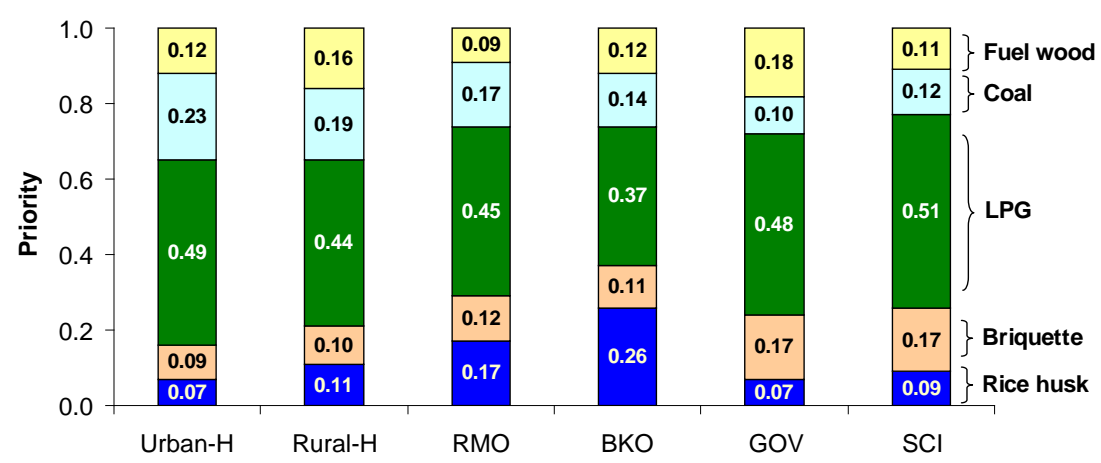

Figure 9. Comparison of “convenience aspects”. 
five fuels. Briquette, coal, and fuel wood showed similar priority weights. Only BKO gave relatively higher priority on rice husk.

After the calculation of weight in each level, the absolute weight of each attribute in the whole hierarchy was calculated by multiplying all the umbrella weights for the attribute. For example, the absolute "global warming" weight is determined by multiplying the weights of "environmental impact" and "global warming". The calculated absolute weights can be directly compared between the different stakeholders. The attribute showing $\geq 0.1$ were picked up and shown in Table 3. While the rural households, rice mill owners, and brick kiln owners paid attention on cost and safety of current uses, the governors paid attention on "water pollution" problem, "safety", and "convenience" of new technologies.

\subsection{Scenario Evaluation Incorporating AHP Results}

The ranks based on LCA estimation and fuel allocation are shown in Table 4. In the cases of "safety" and "convenience", the fuel allocation for the technology was multiplied by the AHP weight of the fuel or the technology. Based on the indexes, the overall rakings of all scenarios were calculated as shown in Table 5. From the results

Table 3. Absolute evaluation of each attribute.

\begin{tabular}{|c|c|c|c|c|c|c|c|c|c|c|c|}
\hline & \multicolumn{4}{|c|}{ Environmental impact } & \multirow{2}{*}{ Cost } & \multicolumn{4}{|c|}{ Safety } & \multicolumn{2}{|c|}{ Convenience } \\
\hline & Global & Water & Air & Waste & & Cooking & Combustion & Gasification & Pyrolyis & Rice husk & LPG \\
\hline Urban-H & 0.05 & 0.11 & 0.06 & 0.05 & 0.10 & 0.11 & 0.09 & 0.15 & 0.10 & 0.02 & 0.10 \\
\hline Rural-H & 0.03 & 0.08 & 0.06 & 0.03 & 0.22 & 0.14 & 0.08 & 0.07 & 0.05 & 0.03 & 0.10 \\
\hline RMO & 0.02 & 0.06 & 0.05 & 0.03 & 0.30 & 0.11 & 0.09 & 0.06 & 0.05 & 0.04 & 0.10 \\
\hline BKO & 0.03 & 0.07 & 0.06 & 0.04 & 0.32 & 0.08 & 0.08 & 0.06 & 0.04 & 0.05 & 0.08 \\
\hline GOV & 0.07 & 0.10 & 0.06 & 0.05 & 0.09 & 0.02 & 0.14 & 0.13 & 0.06 & 0.02 & 0.13 \\
\hline SCI & 0.07 & 0.07 & 0.08 & 0.02 & 0.23 & 0.05 & 0.07 & 0.04 & 0.04 & 0.03 & 0.16 \\
\hline
\end{tabular}

Table 4. Estimated ranks based on LCA estimates and fuel allocation*.

\begin{tabular}{|c|c|c|c|c|c|c|c|c|}
\hline \multirow{2}{*}{$\begin{array}{l}\text { Rice husk use } \\
\text { technology }\end{array}$} & \multirow[b]{2}{*}{ Scenario } & \multicolumn{4}{|c|}{ Environmental impact } & \multirow[b]{2}{*}{ Cost } & \multirow[b]{2}{*}{ Safety } & \multirow[b]{2}{*}{ Convenience } \\
\hline & & $\begin{array}{l}\text { Climate } \\
\text { change }\end{array}$ & $\begin{array}{c}\text { Water } \\
\text { pollution }\end{array}$ & $\begin{array}{c}\text { Air } \\
\text { pollution }\end{array}$ & $\begin{array}{c}\text { Waste } \\
\text { management }\end{array}$ & & & \\
\hline \multirow{4}{*}{ Cooking } & $\mathrm{S} 1$ & 16 & 9.5 & 14 & 9.5 & 1 & 5.5 & 15 \\
\hline & S1B1 & 15 & 9.5 & 3 & 9.5 & 4 & 5.5 & 16 \\
\hline & S1B2 & 13 & 9.5 & 7 & 9.5 & 2 & 5.5 & 18 \\
\hline & S1B3 & 14 & 9.5 & 4 & 9.5 & 3 & 5.5 & 17 \\
\hline \multirow{8}{*}{$\begin{array}{l}\text { Combustion } \\
\text { power plant }\end{array}$} & $\mathrm{S} 2 \mathrm{a}$ & 12 & 9.5 & 13 & 9.5 & 9 & 11.5 & 12 \\
\hline & $\mathrm{S} 4 \mathrm{a}$ & 18 & 9.5 & 5 & 9.5 & 10 & 16 & 5 \\
\hline & $\mathrm{S} 2 \mathrm{Ba}$ & 5 & 9.5 & 15 & 9.5 & 15 & 11.5 & 8.5 \\
\hline & $\mathrm{S} 4 \mathrm{Ba}$ & 10 & 9.5 & 8 & 9.5 & 18 & 16 & 1.5 \\
\hline & $\mathrm{S} 2 \mathrm{~b}$ & 7 & 9.5 & 16 & 9.5 & 8 & 11.5 & 12 \\
\hline & S4b & 11 & 9.5 & 9 & 9.5 & 5 & 16 & 5 \\
\hline & $\mathrm{S} 2 \mathrm{Bb}$ & 1 & 9.5 & 18 & 9.5 & 11 & 11.5 & 8.5 \\
\hline & $\mathrm{S} 4 \mathrm{Bb}$ & 4 & 9.5 & 11 & 9.5 & 12 & 16 & 1.5 \\
\hline \multirow{4}{*}{$\begin{array}{l}\text { Gasification } \\
\text { power plant }\end{array}$} & S3a & 9 & 9.5 & 12 & 9.5 & 7 & 2.5 & 12 \\
\hline & S5a & 17 & 9.5 & 6 & 9.5 & 6 & 1 & 5 \\
\hline & S3b & 2 & 9.5 & 17 & 9.5 & 14 & 2.5 & 12 \\
\hline & S5b & 6 & 9.5 & 10 & 9.5 & 17 & 16 & 5 \\
\hline \multirow{2}{*}{ Pyrolysis } & S6 & 8 & 9.5 & 2 & 9.5 & 13 & 8 & 12 \\
\hline & S7 & 3 & 9.5 & 1 & 9.5 & 16 & 9 & 5 \\
\hline
\end{tabular}

${ }^{*}$ Higher rank means worse evaluation. 
Table 5. Scenario evaluation results from preferences of six stakeholder groups.

\begin{tabular}{cccccccc}
\hline Rice husk use technology & Scenarios & Urban-H & Rural-H & RMO & BKO & GOV & SCI \\
\hline \multirow{2}{*}{ Cooking } & S1 & 9 & $\mathbf{1}$ & $\mathbf{1}$ & $\mathbf{1}$ & 18 & 15 \\
& S1B1 & 4 & 4 & 6 & 5 & 12 & $\mathbf{2}$ \\
& S1B2 & 7 & $\mathbf{2}$ & $\mathbf{2}$ & $\mathbf{2}$ & 15 & 12 \\
& S1B3 & 5 & $\mathbf{3}$ & $\mathbf{3}$ & $\mathbf{3}$ & 13 & $\mathbf{3}$ \\
& S2a & 14 & 6 & 5 & 6 & 9 & 9 \\
Combustion power plant & S4a & 10 & 10 & 9 & 9 & 6 & 10 \\
& S2Ba & 15 & 13 & 13 & 14 & 4 & 6 \\
& S4Ba & 13 & 18 & 18 & 18 & $\mathbf{2}$ & 4 \\
& S2b & 17 & 5 & 4 & 4 & 8 & 8 \\
Pyrolysis & S4b & 11 & 7 & 7 & 7 & 5 & 7 \\
& S2Bb & 16 & 9 & 10 & 11 & $\mathbf{3}$ & 5 \\
& S4Bb & 12 & 17 & 15 & 15 & $\mathbf{1}$ & $\mathbf{1}$ \\
& S3a & $\mathbf{3}$ & 8 & 8 & 8 & 11 & 11 \\
\hline
\end{tabular}

${ }^{*}$ Higher rank means worse evaluation.

of the overall ranking, the preferable scenarios were identified for each stakeholder. Rural-H, RMO, and BKO preferred rice husk use in cooking (S1, S1B1, S1B3), while Urban-H preferred rice husk gasification (S5b, S3a, $\mathrm{S} 3 \mathrm{~b}$ ). GOV and SCI wanted to use rice husks in combustion power plants (S4Bb, S4Bb, S4b); their preferences were completely opposite to those of the local residents.

\section{Conclusions and Recommendations}

By incorporating the LCA results with the results of the AHP model, it was found that rural households, rice mill owners, and brick kiln owners still want to use rice husk in conventional ways, while urban households, government officials, and scientists prefer to use rice husk with new technologies. The big gaps between these two groups were revealed through the objective analysis of people's preferences instead of directly asking for their scenario preferences.

The results reveal the aspect that each stakeholder thinks is important and the conflict between stakeholders. This study can indicate the people's opinion and, as a consequence, it can help the government to optimize an information campaign for the population as well as in decision-making for rice husk use strategy. These results can also be a good communication tool for Non-Governmental Organizations (NGOs) and residents to make their preferences heard by decision makers, thereby making decision-making a shared and systematic process between government officials and the local people. Our results may help simplify and expedite the decisionmaking process by supplying the quantitative and qualitative information for decision makers, and thus resulting in more attractive and effective decision making. Generally, our methodology is useful to understand current preferences and for short-term decision-making. However, there is also the limitation in applying our results to the distant future: it is difficult to know how technology will develop and how the awareness of the stakeholders will change in the long-term. 
The questionnaire survey that applied the modified AHP procedure may be another source of limitation. The pair-wise judgment of each technology under the "safety" viewpoint may involve the total impression of each technology, in addition to the "safety" aspect. The possible solution to this problem would be additional questions about preference on "technology itself". The effect of the total impression on technologies can be investigated through comparisons between the answers for "technology itself" and "safety". The questionnaire can be improved to prevent various biases in future studies.

\section{Acknowledgements}

This study is financially supported by a Grant-in-Aid for Scientific Research (B) from the Ministry of Education, Culture, Sports, Science and Technology of Japan (Project leader: Toshiya Aramaki, Toyo University). We also extend our thanks to the An Giang People's Committee for their cooperation and help with the local survey in An Giang.

\section{References}

[1] Nguyen, N.T. and Duong, H.M. (2009) Economic Potential of Renewable Energy in Vietnam's Power Sector. Energy Policy, 37, 1601-1613. http://dx.doi.org/10.1016/j.enpol.2008.12.026

[2] PREGA National Technical Experts (2004) Demonstration of Rice Rusks Fired Power Plant in An Giang Province: A Pre-Feasibility Study Report. Vietnam Institute of Energy, Hanoi.

[3] PREGA National Technical Experts (2006) Bagasse and Other Biomass-Fired Power Plant in Ben Tre Sugar Company: A Pre-Feasibility Study Report. Vietnam Institute of Energy, Hanoi.

[4] Nguyen, V.H. and Nguyen, V.S. (2006) Clean Development Mechanism Project Design Documents (CDM-PDD) for Pilot Grid Connected Rice Husk Fueled Bio-Power Development Projects in Mekong Delta, Vietnam: Second Technical Report. EEPSEA, Hanoi. www.idrc.ca/uploads/user-S/11624356301Hanh.doc

[5] Kellett, J. (2007) Community-Based Energy Policy: A Practical Approach to Carbon Reduction. Journal of Environmental Planning and Management, 50, 381-396. http://dx.doi.org/10.1080/09640560701261679

[6] Angiang (2007) Angiang's Statistics Yearbook. Statistical Publishing House, Hanoi.

[7] Thao, P.T.M., Kurisu, K.H. and Hanaki, K. (2011) Greenhouse Gas Emission Mitigation Potential of Rice Husks for An Giang Province, Vietnam. Biomass Bioenergy, 35, 3656-3666. http://dx.doi.org/10.1016/j.biombioe.2011.05.023

[8] Thao, P.T.M., Kurisu, K.H. and Hanaki, K. (2012) Evaluation of Strategies for Utilizing Rice Husk Based on Life Cycle Cost Analysis in Relation to Greenhouse Gas Emissions in An Giang Province, Vietnam. Biomass and Bioenergy, 37, 122-131. http://dx.doi.org/10.1016/j.biombioe.2011.12.021

[9] Saaty, T.L. (1980) The Analytic Hierarchy Process. McGraw-Hill, New York.

[10] Qureshi, M.E. and Harrison, S.R. (2003) Application of the Analytic Hierarchy Process to Riparian Revegetation Policy Options Small-Scale Forest Economics. Management and Policy, 2, 441-458.

[11] Coyle, G. (2004) The Analytic Hierarchy Process (AHP). http://www.booksites.net/download/coyle/student_files/AHP_Technique.pdf

[12] Dodd, F.J., Donegan, H.A. and McMaster, T.B.M. (1995) Inverse Inconsistency in Analytic Hierarchies. European Journal of Operational Research, 80, 86-93. http://dx.doi.org/10.1016/0377-2217(94)E0342-9

[13] Tung, S.L. and Tang, S.L. (1998) A Comparison of the Saaty's AHP and Modified AHP for Right and Left Eigenvector Inconsistency. European Journal of Operational Research, 106, 123-128. http://dx.doi.org/10.1016/S0377-2217(98)00353-1 
Scientific Research Publishing (SCIRP) is one of the largest Open Access journal publishers. It is currently publishing more than 200 open access, online, peer-reviewed journals covering a wide range of academic disciplines. SCIRP serves the worldwide academic communities and contributes to the progress and application of science with its publication.

Other selected journals from SCIRP are listed as below. Submit your manuscript to us via either submit@scirp.org or Online Submission Portal.
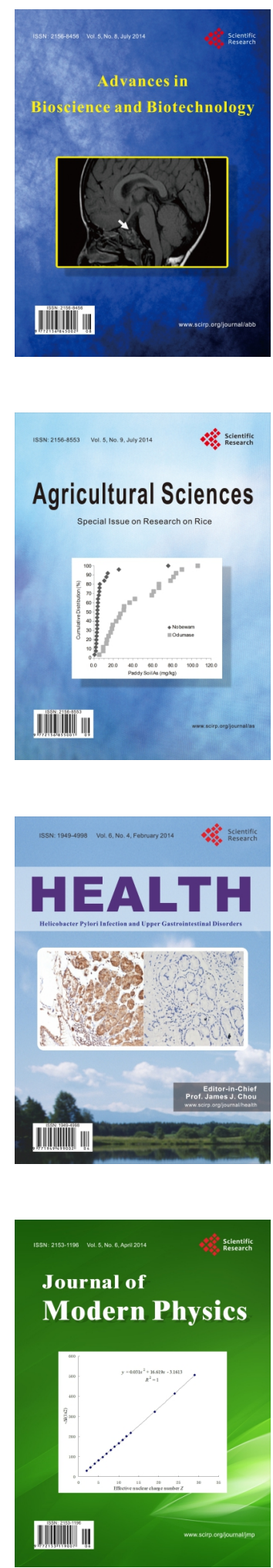
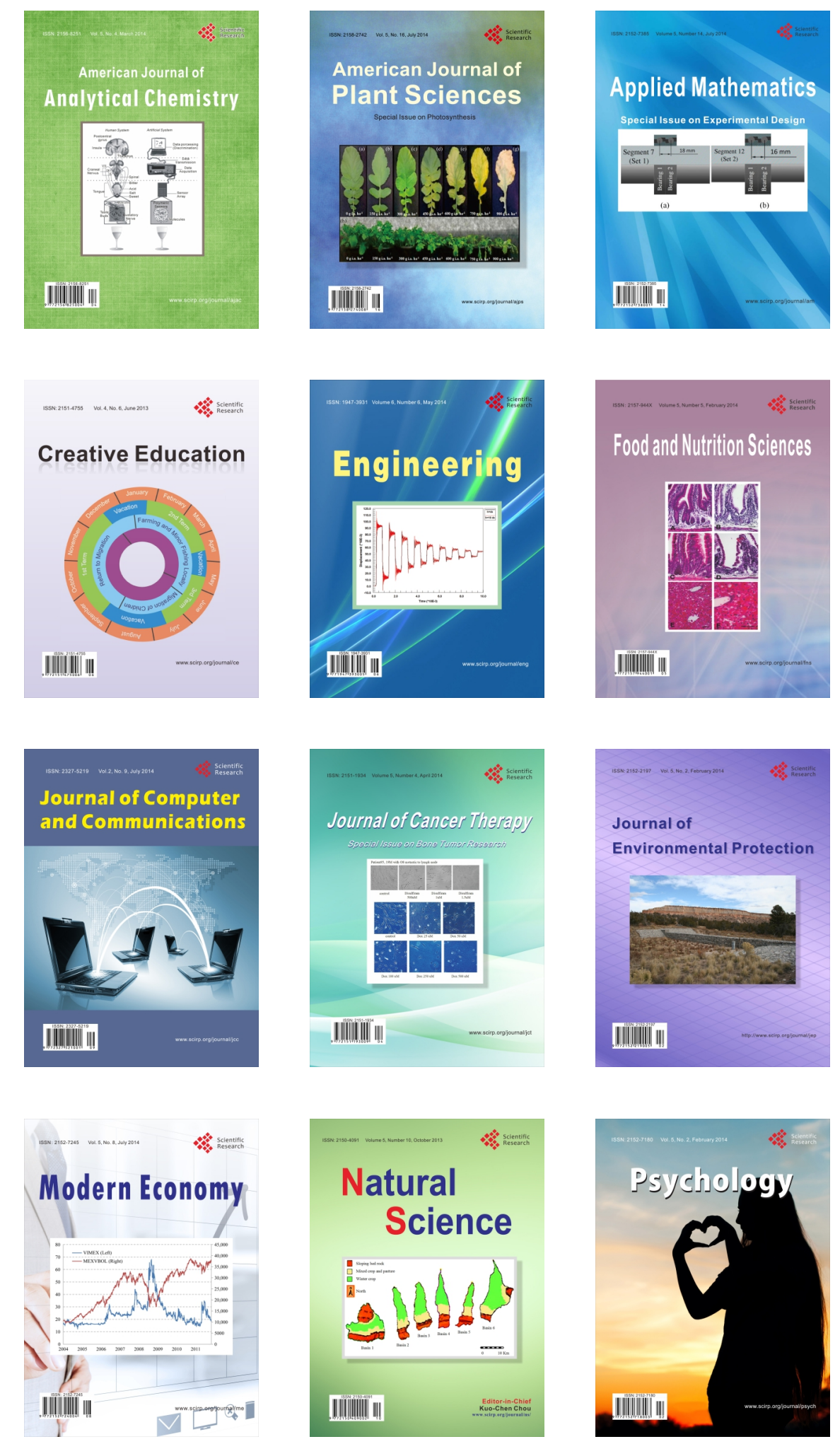